\title{
Simulation and Experimental Verification of a HB-Type Vernier Motor
}

\author{
Rabee' Hashim Thejel \\ Department of Electrical Engineering \\ University of Basrah \\ Basrah, Iraq \\ rabee_alabbasi@yahoo.com
}

\author{
Haroutuon A. Hairik \\ Department of Electrical Engineering \\ University of Basrah \\ Basrah, Iraq \\ haroutuonhairik@ymail.com
}

\author{
Mazin Abdulelah Alwan \\ Department of Electrical \\ Engineering \\ University of Basrah \\ Basrah, Iraq \\ mazin_alwan@yahoo.com
}

\begin{abstract}
Direct drive motors are used as actuators in numerous applications in which they must rotate at low speeds with high torque and low torque ripple. Various types of vernier motors have been studied recently. The HB type vernier motor is one of them. Its rotor structure is the same as in a $\mathrm{HB}$ type stepping motor but has a field winding at the rotor and has multiphase windings in the stator. In the present work, a Matlab simulation of a HB type vernier motor is presented. To validate the motor results and response, the authors fabricated the motor and implemented its drive circuit. The motor was tested for different load conditions. Experimental results are found identical to simulation results and it is also shown that the motor has low torque ripple.
\end{abstract}

Keywords-direct drive; actuator; HB-type; vernier; Matlab

LIST OF SYMBOLS

$E_{o} \quad$ Electromotive force (V).

$f$ Frequency $(\mathrm{Hz})$.

$I_{F} \quad$ Field current (A).

$N_{l} \quad$ Number of turns of phase "a".

$\mathrm{N}_{2} \quad$ Number of rotor single coil turns.

$N_{s p} \quad$ Synchronous speed (r.p.m).

$p \quad$ Differential operator $(\mathrm{d} / \mathrm{dt})$.

$r_{l} \quad$ Stator winding resistance per phase $(\Omega)$.

$r_{F} \quad$ Rotor winding resistance $(\Omega)$.

$T_{e} \quad$ Electric torque (Nm).

$T_{L} \quad$ Load torque $(\mathrm{Nm})$.

$X_{S} \quad$ Synchronous reactance $(\Omega)$.

$\alpha \quad$ Phase shift for three phase or in general $=\frac{2 \pi}{\mathrm{m}}$.

$\delta_{L} \quad$ Power angle (rad).

$\omega_{1} \quad$ Supply angular frequency $(\mathrm{rad} / \mathrm{sec})$.

$\omega_{m} \quad$ Rotor Angular speed $(\mathrm{rad} / \mathrm{sec})$.

$2 \theta_{1} \quad$ Stator Coil Pitch $=\frac{2 \pi}{\mathrm{N}_{\mathrm{S}}}$.
$2 \theta_{2} \quad$ Rotor Coil Pitch $=\frac{2 \pi}{2 \mathrm{~N}_{\mathrm{R}}}$.

$\theta^{\prime} \quad$ Angle between the rotor adjacent $\mathrm{N}$-silent pole and S-silent pole.

\section{INTRODUCTION}

Application of direct drive systems in robot and factory automation is constantly increasing, due to their controllability and high accuracy, requiring motors with high torque at low speed. Stepping motors and DC brushless motors are used as direct drive motors. A stepping motor has a concentrated stator winding and is driven by a pulse-shaped exaction voltage. Therefore, in principle, torque pulsation exists during rotation. Meanwhile, various types of vernier motors have been developed, such as variable reluctance vernier motors and permanent magnet vernier motors. The latest is probably the HB type vernier motor which has the advantage of low torque ripple. The construction of the $\mathrm{HB}$ type vernier motor requires a field winding in the rotor and multiphase distributed winding in the stator. As a result, the HB type vernier motor is identical to a general synchronous machine in regards of voltage equation and torque formula $[1,2]$. In this paper, the mathematical model of the HB type vernier motor is described and the Matlab/Simulink software package is used to study the dynamic motor responses due to normal and sudden load torque. To validate the simulation, the authors fabricated a motor and implemented a drive circuit. A sudden load torque was applied to the motor shaft by using a loading device and motor torque response was recorded. Results are presented and discussed.

\section{STRUCTURE OF HB-TYPE VERNIER MOTOR AND EXPERIMENTAL DESIGN}

The motor is a vernier-synchronous type and is not selfstarting in the speed range of 50 to $150 \mathrm{rpm}$. It is started with a special starting circuit at reduced frequency and then gradually increased to the actual speed [3].

The stator of the HB-type vernier motor has $N_{S}$ slots. These slots have ordinary three-phase windings [4] with $N_{P}$ number of 
poles. The rotor consists of two parts which pinches the field windings that axially penetrate the flux in the rotor as shown in Figure 1.

Each rotor part consists of a number of salient poles $\left(N_{R}\right)$. The first part contains the $\mathrm{N}$-magnetized salient poles and the second part contains the S-magnetized salient poles which are deviated by half a slot in the circumferential direction. Thus, these poles are appears alternately. The rotating magnetic fields in the gap are the basic wave fields generated by the three winding of the stator and the $\left(N_{S} \pm N_{P} / 2\right)$ degree harmonic (slot harmonic) field by pulsation of the gap permeance distribution attributable to the stator slots.

The rotor rotates in synchronization with the slot harmonic rotating magnetic field. The main relationship to design the HB-type vernier motor which is similar to the HB-type stepper motor is given by [4]:

$$
N_{S} \pm \frac{N_{P}}{2}=N_{R}
$$

The synchronous speed of the HB-type vernier motor is expressed as shown below:

$$
N_{s p}=\frac{120 f}{N_{P}} \frac{N_{P}}{2 N_{R}}=\frac{120 f}{2 N_{R}}
$$

For the present motor, which has $N_{S}=36, N_{R}=30$, and $N_{P}=12$, if $f=50 \mathrm{~Hz}$, the synchronous speed is $100 \mathrm{rpm}$.

\section{VOLTAGE EQUATION AND TORQUE FORMULA}

The motor has three phase windings in the stator and a field winding in the rotor. Thus, the inductance matrix of the present HB-type vernier motor has $4 \times 4$ size and can be written as given in $(3)[5,6]$ :

$$
[L]=\left[\begin{array}{ccc}
L_{1}+L_{m} & -\frac{L_{m}}{2} \\
-\frac{L_{m}}{2} & L_{1}+L_{m} & \\
-\frac{L_{m}}{2} & -\frac{L_{m}}{2} & \\
M_{R} \cos N_{R} \theta^{\prime} & M_{R} \cos N_{R}\left(\theta^{\prime}-\alpha\right) & M_{R} \cos N_{R} \theta^{\prime} \\
-\frac{L_{m}}{2} & M_{R} \cos N_{R}\left(\theta^{\prime}-\alpha\right) \\
-\frac{L_{m}}{2} & M_{R} \cos N_{R}\left(\theta^{\prime}-2 \alpha\right) \\
L_{1}+L_{m} & L_{F}
\end{array}\right]
$$

where, $L_{l}$ is the self inductance of the stator winding per phase, $L_{m}$ is the mutual inductance between stator phases, $M_{R}$ is the mutual inductance between the stator phase winding and the rotor winding, and $L_{F}$ is the self inductance of the rotor winding, $\theta^{\prime}$ is the angle between the rotor adjacent $\mathrm{N}$-silent pole and the S-silent pole, $\alpha$ is the stator winding phase shift for three phase equal to $\left(\frac{2 \pi}{3}\right)$.

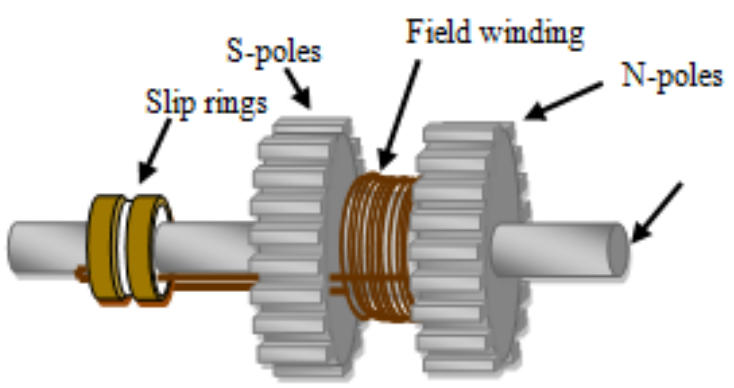

Shaft

Fig. 1. Rotor of HB-type Vernier motor

The voltage equation of the HB-type vernier motor is similar to those for a general synchronous machine and is given by $[1,2]$ :

$$
[v]=\{[r]+p[L]\} \cdot[i]
$$

where $p=d / d t$.

Substituting for the inductance matrix $[L]$ from (3) into (4) gives:

$$
\left[\begin{array}{c}
v_{a} \\
v_{b} \\
v_{c} \\
v_{F}
\end{array}\right]=\left[\begin{array}{cc}
r_{l}+p\left(L_{l}+L_{m}\right) & -p \frac{L_{m}}{2} \\
-p \frac{L_{m}}{2} & r_{I}+p\left(L_{I}+L_{m}\right) \\
-p \frac{L_{m}}{2} & -p \frac{L_{m}}{2} \\
p M_{R} \cos N_{R} \theta^{\prime} & p M_{R} \cos N_{R}\left(\theta^{\prime}-\alpha\right)
\end{array}\right.
$$

$$
\left.\begin{array}{cc}
-p \frac{L_{m}}{2} & p M_{R} \cos N_{R} \theta^{\prime} \\
-p \frac{L_{m}}{2} & p M_{R} \cos N_{R}\left(\theta^{\prime}-\alpha\right) \\
+p\left(L_{1}+L_{m}\right) & p M_{R} \cos N_{R}\left(\theta^{\prime}-2 \alpha\right) \\
\cos _{R}\left(\theta^{\prime}-2 \alpha\right) & r_{F}+p L_{F}
\end{array}\right] \cdot\left[\begin{array}{c}
i_{a} \\
i_{b} \\
i_{c} \\
i_{F}
\end{array}\right]
$$

on the condition that a balanced three-phase voltage is applied and a balanced three-phase current flows through the motor. The synchronous torque of the HB-type vernier motor is expressed as follows:

$$
T=\frac{3}{\omega_{1}} \cdot N_{R} \cdot \frac{V E_{o}}{X_{S}} \cdot \sin \left(N_{R} \delta_{L}\right)
$$

where $E_{o}$ is the induced electromotive force and $X_{S}$ is the synchronous reactance, expressed as follows:

$$
\begin{gathered}
E_{o}=\frac{\omega_{1}}{\sqrt{3}} M_{F} i_{F} \\
X_{S}=\omega_{1}\left(L_{1}+\frac{3}{2} L_{m}\right) a
\end{gathered}
$$

where, $M_{F}=\sqrt{\frac{3}{2}} M_{R}$ 
The usefulness of transforming an abc-reference frame to a dq-reference frame stems from the fact that although each of the stator phases sees a time-varying inductance due to the saliency of the rotor, the transformed quantities rotate with the rotor and hence see constant magnetic paths [6].

The relationship between a set of $\mathrm{dq}$ variables and the corresponding set of three-phase abc variables is provided by the transformation matrix $T d q$. Since the three-phase systems studied in this research are balanced, no 0 -axis components are present, which allows using a simplified version of dqtransformation [5]:

$$
\left[\begin{array}{c}
v_{d} \\
v_{q}
\end{array}\right]=T_{d q}\left[\begin{array}{l}
v_{a} \\
v_{b} \\
v_{c}
\end{array}\right]
$$

where

$$
T_{d q}=\frac{2}{3}\left[\begin{array}{ccc}
\cos \omega_{m} t & \cos \left(\omega_{m} t-\frac{2 \pi}{3}\right) & \cos \left(\omega_{m} t+\frac{2 \pi}{3}\right) \\
\sin \omega_{m} t & \sin \left(\omega_{m} t-\frac{2 \pi}{3}\right) & \sin \left(\omega_{m} t+\frac{2 \pi}{3}\right)
\end{array}\right]
$$

and $\omega_{m}$ is the speed $(\mathrm{rad} / \mathrm{sec})$ of the rotating frame.

The inverse transformation from $\mathrm{dq}$ to abc currents is defined as:

$$
\left[\begin{array}{c}
i_{a} \\
i_{b} \\
i_{c}
\end{array}\right]=T_{d q}^{-1}\left[\begin{array}{c}
i_{d} \\
i_{q}
\end{array}\right]
$$

By applying (9) on the stator part of (5), simplifying and then adding the rotor part, the dq-model of HB-type vernier motor can be obtained as shown in (12):

$$
\left[\begin{array}{c}
v_{d} \\
v_{q} \\
v_{F}
\end{array}\right]=\left[\begin{array}{ccc}
r_{1}+p\left(L_{1}+\frac{3}{2} L_{m}\right) & -N_{R} \omega_{m}\left(L_{1}+\frac{3}{2} L_{m}\right) & p \sqrt{\frac{3}{2}} M_{R} \\
N_{R} \omega_{m}\left(L_{1}+\frac{3}{2} L_{m}\right) & r_{1}+p\left(L_{1}+\frac{3}{2} L_{m}\right) & -\sqrt{\frac{3}{2}} N_{R} \omega_{m} M_{R} \\
p \sqrt{\frac{3}{2}} M_{R} & 0 & r_{F}+p L_{F}
\end{array}\right] \cdot\left[\begin{array}{c}
i_{d} \\
i_{q} \\
i_{F}
\end{array}\right]
$$

The electromagnetic torque is approximately given by:

$$
T_{e}=-N_{R} M_{F} i_{F} i_{q}
$$

The dynamic equation of the mechanical torque is given by:

$$
J \frac{d \omega_{m}}{d t}=T_{e}-B_{F} \omega_{m}-T_{L}
$$

where, $J$ is the motor moment of inertia (kg.m2), $B_{F}$ is the motor viscous fraction factor $(\mathrm{Nm} / \mathrm{rad} / \mathrm{sec})$, and $T_{L}$ is the mechanical load torque in $\mathrm{Nm}$.

\section{MATLAB SIMULATION}

The first row of (12) can be rearranged as follows:

$$
p i_{d}=\frac{1}{L_{S}}\left[v_{d}-r_{1} i_{d}+L_{S} N_{R} \omega_{m} i_{q}-M_{F} p i_{F}\right]
$$

where, $L_{S}=\left(L_{1}+\frac{3}{2} L_{m}\right)$

The Matlab simulink representation of (15) is given in Figure 2. The second row of (12) is rewritten as:

$$
p i_{q}=\frac{1}{L_{S}}\left[v_{q}-r_{1} i_{q}-L_{S} N_{R} \omega_{m} i_{d}+N_{R} \omega_{m} M_{F} i_{F}\right]
$$

This equation is simulated as shown in Figure 3. The third row of (12) is rearranged in (17) and simulated as shown in Figure

$$
p i_{F}=\frac{1}{L_{F}}\left[v_{F}-M_{F} p i_{d}+r_{F} i_{F}\right]
$$

The overall mathematical model of the HB-type vernier motor given in (13)-(17) is simulated using Matlab. Simulation can be very useful in many scientific studies to formulate a hypothesis or a mathematical model, to explain the observations and to predict the behavior of a system from solutions or properties of the model. The model used is shown in Figure 5, where the "abc to dq" block is given by (9) and the "dq to abc" block is given by (11). The parameters of the present HB-type vernier motor are listed in Table I.

\section{Simulation RESUlts}

The motor drive circuit in this paper consists of a Space Vector Pulse Width Modulation (SVPWM) and a three phase Voltage Source Inverter (VSI). SVPWM is a more sophisticated technique for generating a sine wave that provides a higher voltage to the motor with lower total harmonic distortion [7]. The rotor DC voltage is $v_{F}=28 \mathrm{~V}$.

The Matlab simulation results of ' $a$ ' phase voltages of the SVPWM VSI at $f=50 \mathrm{~Hz}, E=220 \mathrm{~V}$, and $\mathrm{V}_{\mathrm{S}}^{*}=0.55 \mathrm{pu}$. are shown in Figure 6.

The motor model shows that the steady state speed changes linearly with frequency as shown in Figure 7.

The motor behavior due to sudden change of the shaft load is also tested. The motor is first driven at no load, and then the load is suddenly changed to 5 N.m at $t=2 \mathrm{sec}$. The test results of the motor speed and torque are shown in Figures 8-9. The motor three-phase currents are shown in Figure 10. 


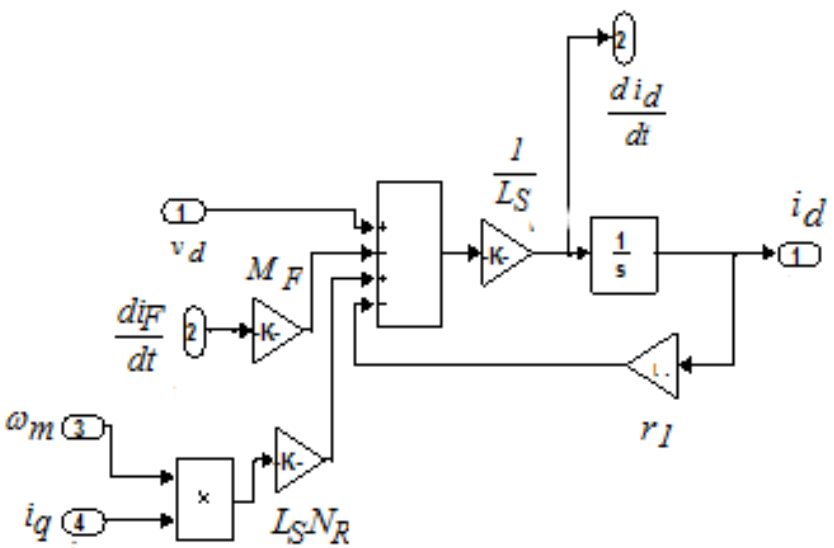

Fig. 2. Implemented Simulink model of (15)

TABLE I.

\begin{tabular}{|c|l|}
\hline $\mathbf{r 1}$ & $0.9 \Omega$ \\
\hline $\mathbf{r F}$ & $2.8 \Omega$ \\
\hline $\mathbf{L 1}$ & $0.055 \mathrm{H}$ \\
\hline $\mathbf{L m}$ & $0.0557 \mathrm{H}$ \\
\hline $\mathbf{M R}$ & $0.0196 \mathrm{H}$ \\
\hline $\mathbf{L F}$ & $0.0178 \mathrm{H}$ \\
\hline $\mathbf{J}$ & $0.01 \mathrm{~kg} . \mathrm{m} 2$ \\
\hline $\mathbf{B}$ & $0.05 \mathrm{Nm} / \mathrm{rad} / \mathrm{sec}$ \\
\hline
\end{tabular}

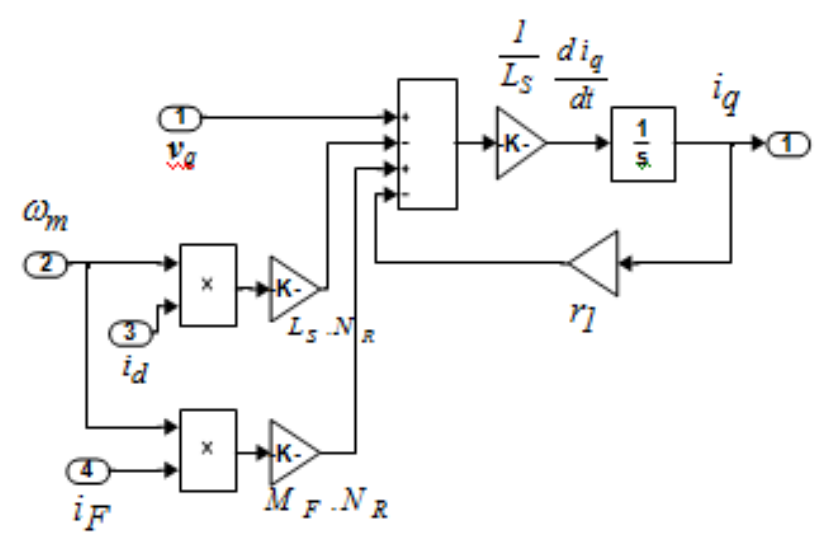

Fig. 3. Implemented Simulink model of (16)

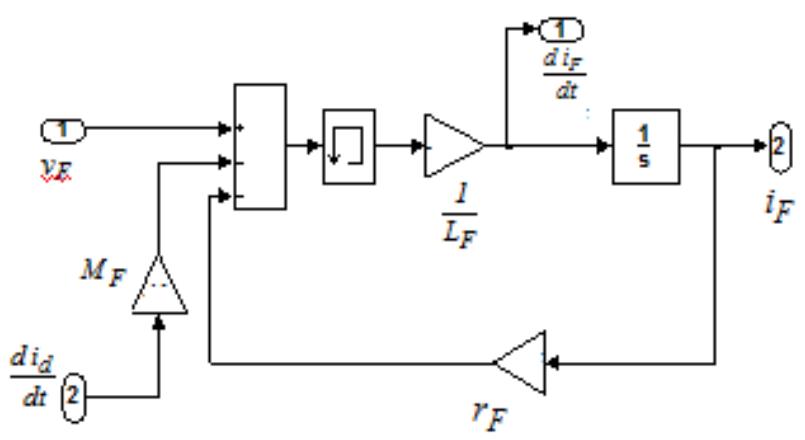

Fig. 4. Implemented Simulink model of (17)

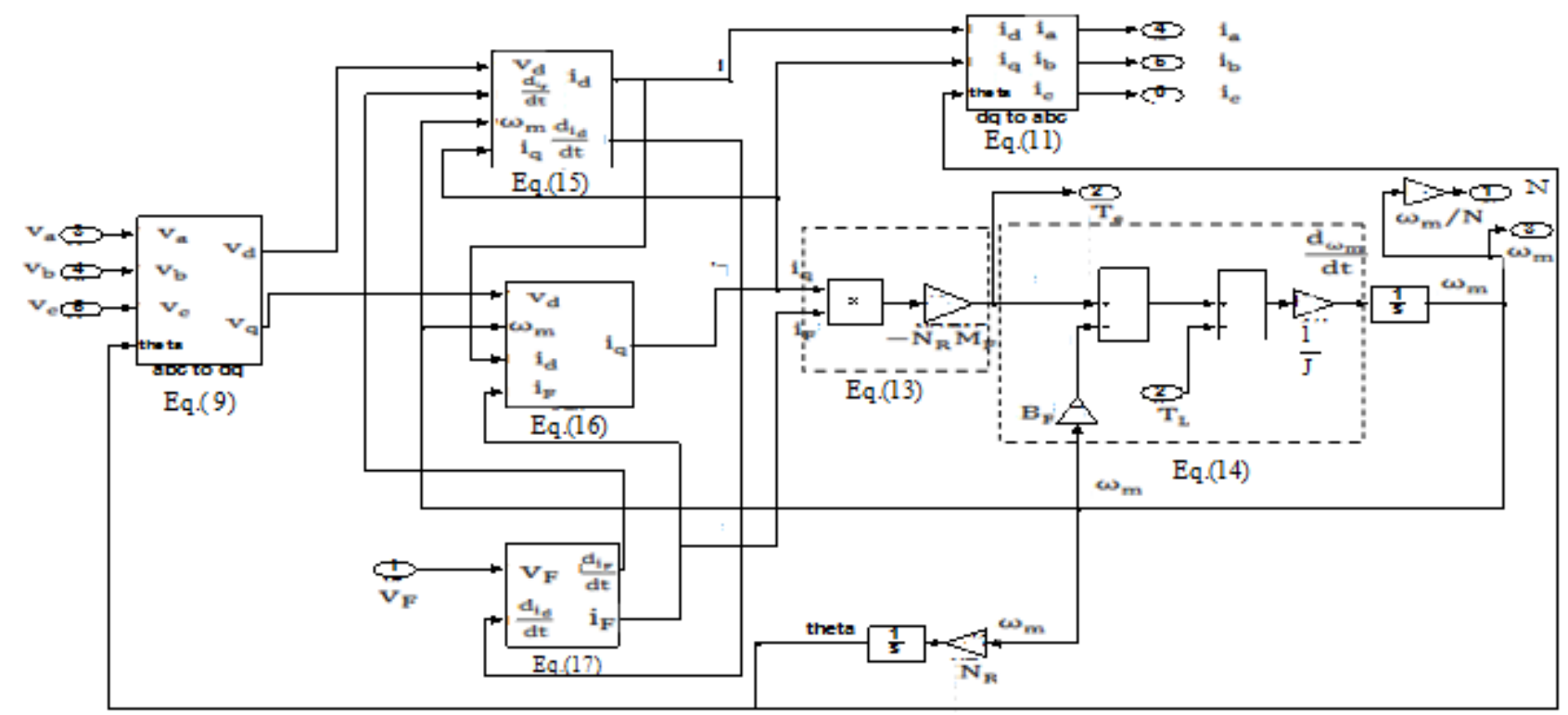

Fig. 5. Implemented Simulink model of the complete motor dq-model 


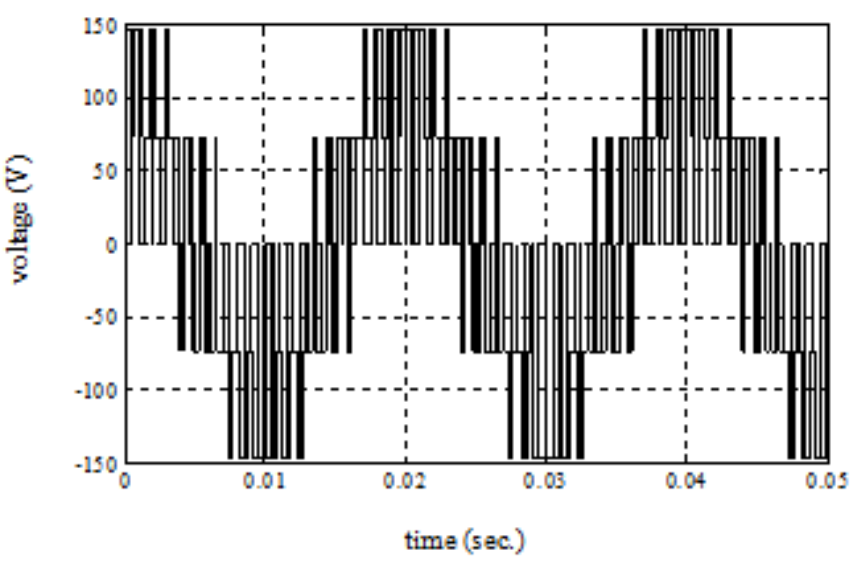

Fig. 6. Inverter phases 'a' voltage when $f=50 \mathrm{~Hz}, \mathrm{~V}_{\mathrm{S}}^{*}=0.55 \mathrm{pu}$

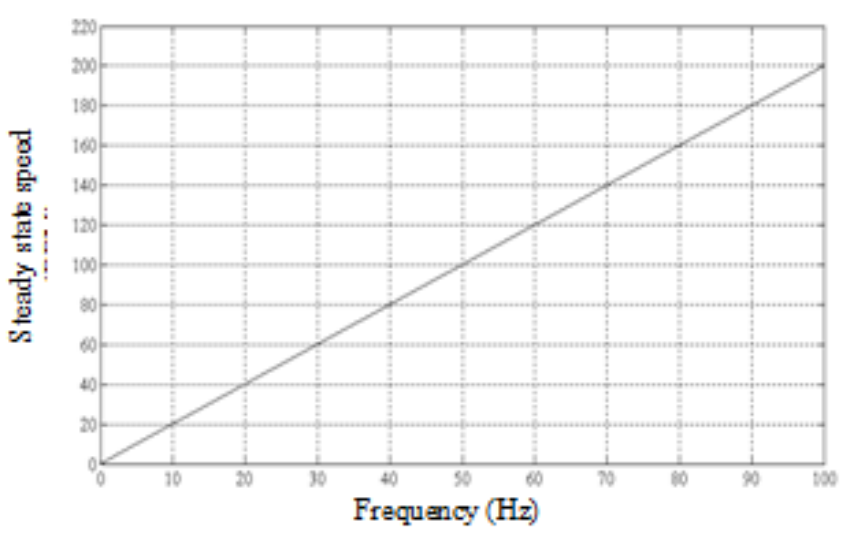

Fig. 7. Steady state speed-frequency curve of HB type vernier motor

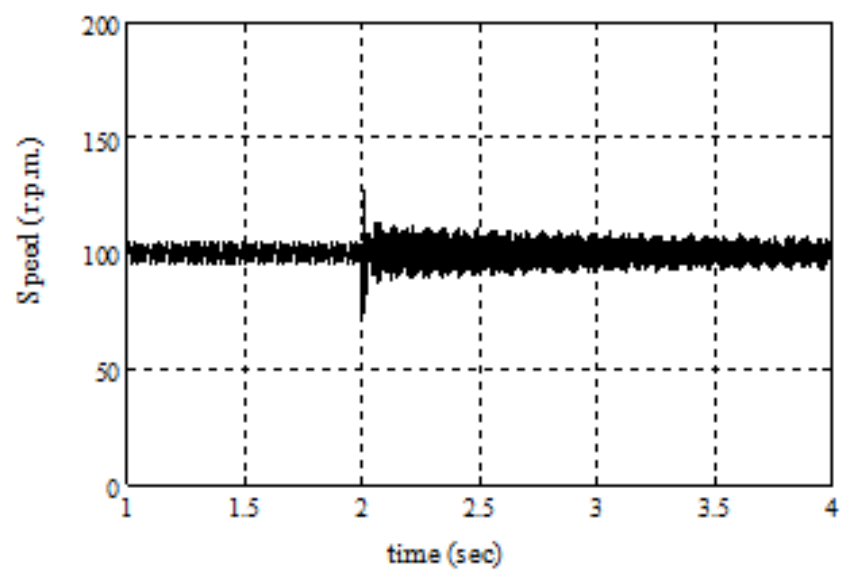

Fig. 8. Speed response of the HB type vernier motor

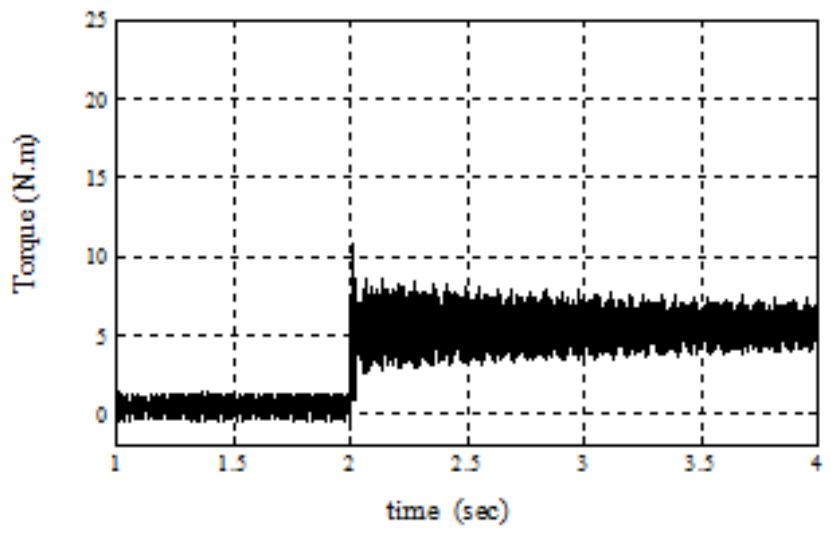

Fig. 9. Torque response of the HB type vernier motor

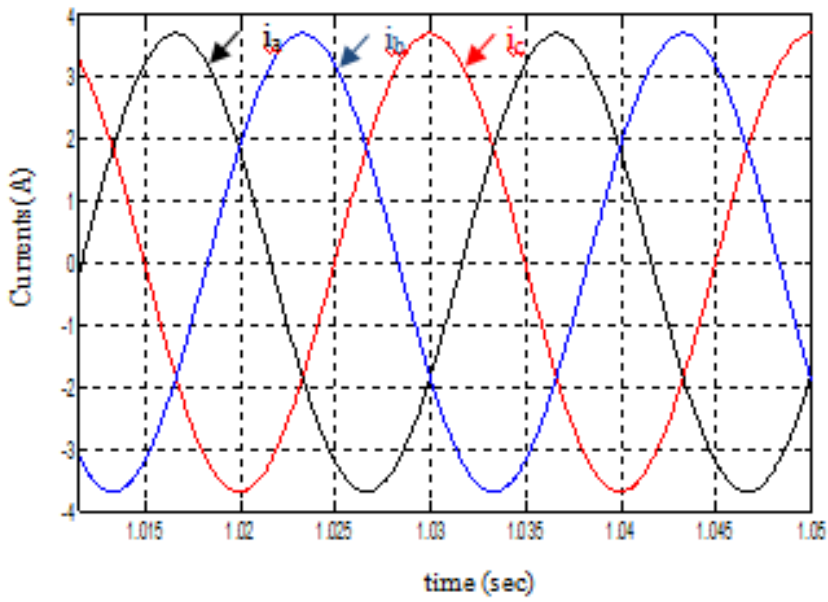

Fig. 10. Three phase currents of the HB type vernier motor.

\section{EXPERNIMTAL IMPLEMENTATION}

The motor was fabricated in order to validate the motor mathematical model simulation. The motor specifications are given in Table II:

TABLE II. SPECIFICATION OF TEST MOTOR.

\begin{tabular}{|c|l|}
\hline Outside diameter of rotor & $110 \mathrm{~mm}$ \\
\hline Inside diameter of stator & $111 \mathrm{~mm}$ \\
\hline Core length & $89 \mathrm{~mm}$ \\
\hline Number of stator turns per phase & 336 \\
\hline Number of field turns & 305 \\
\hline
\end{tabular}

The stator of the motor has 36 slots and is wounded with three phase windings with 12 poles as shown in Figure 11.

The rotor of the motor has 30 silent poles in each side. The field winding is supplied with DC current through two slip rings as shown in Figure 12. 


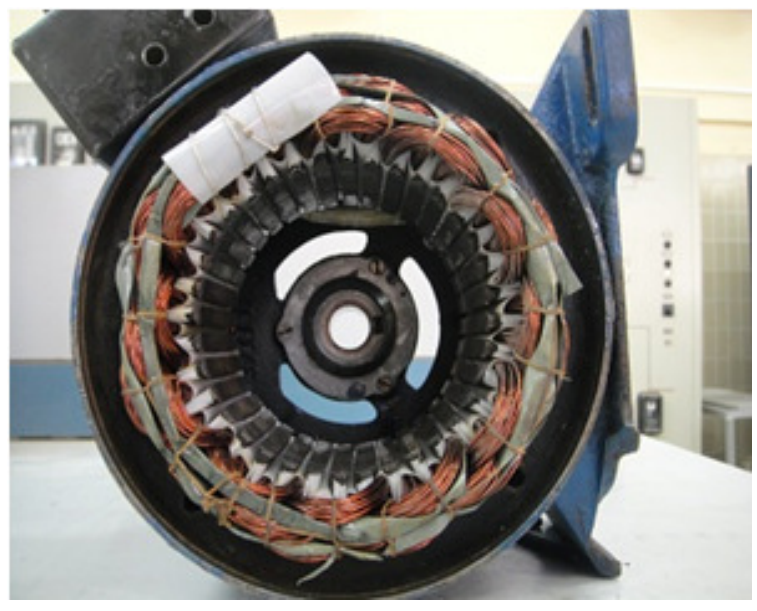

Fig. 11. Stator of test Vernier motor

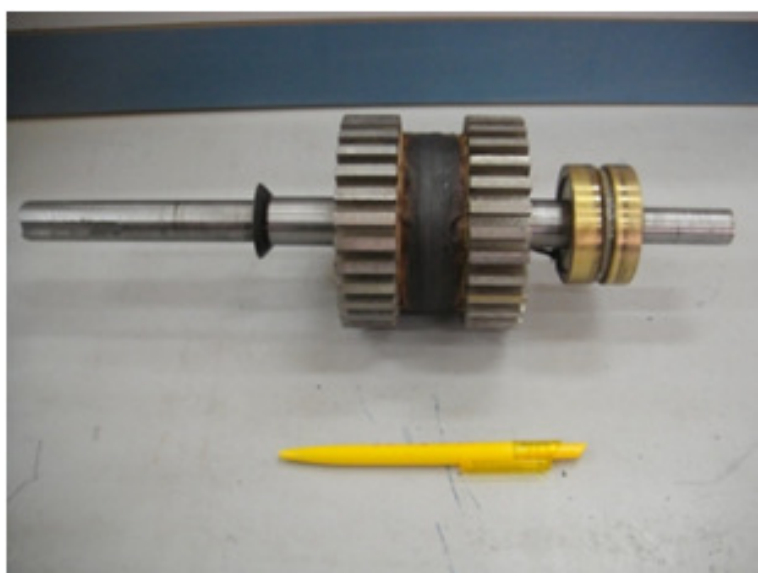

Fig. 12. Rotor of test Vernier motor

The experimental motor drive circuit is based on the space vector technique and is consisted of two main parts, three phase inverters and a PC computer interface with an inverter to generate six gates pluses based on SVPWM as shown in Figure 13.

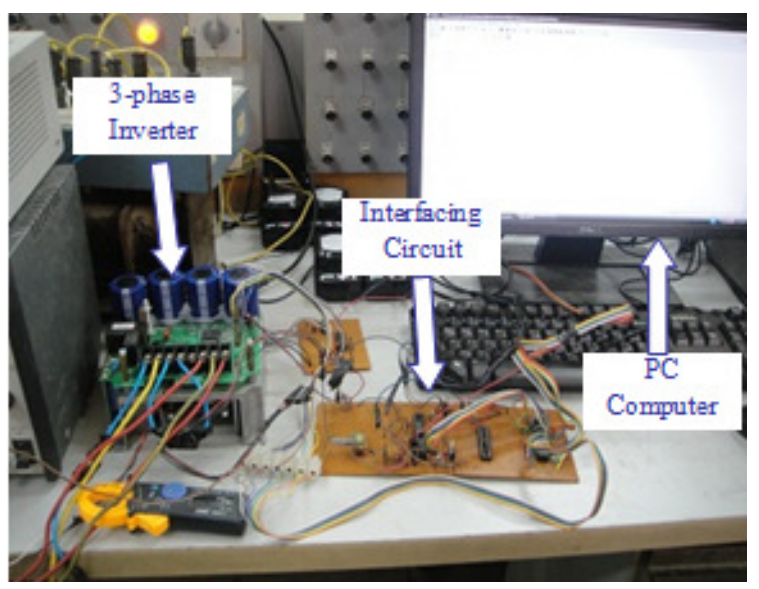

Fig. 13. Motor drive circuit

\section{EXPERIMENTAL RESULTS}

The motor is not self-starting for a frequency range greater than $20 \mathrm{~Hz}$. It is started with low frequency increasing step by step until it reaches $50 \mathrm{~Hz}$. The speed of the motor is measured by using a shaft encoder connected on the motor shaft. The experimental motor speed profiles at starting and steady state are shown in Figure 14.

The motor phase voltage and current are shown in Figure 15. The motor is tested for sudden load changes by using a loading device as shown in Figure 16.

The motor is tested for two cases. At first, the motor operates with no load and then a sudden load of $5 \mathrm{Nm}$ is applied. In the second case, the load is suddenly removed from the motor. The results show that the motor has a short period of torque oscillation as shown in Figures 17 and 18.

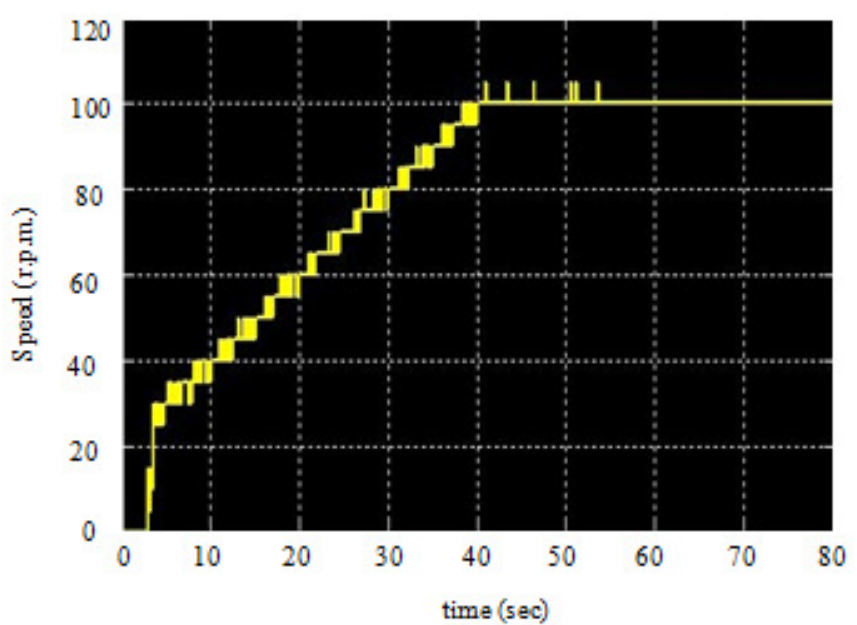

Fig. 14. Experimental speed profile of the motor

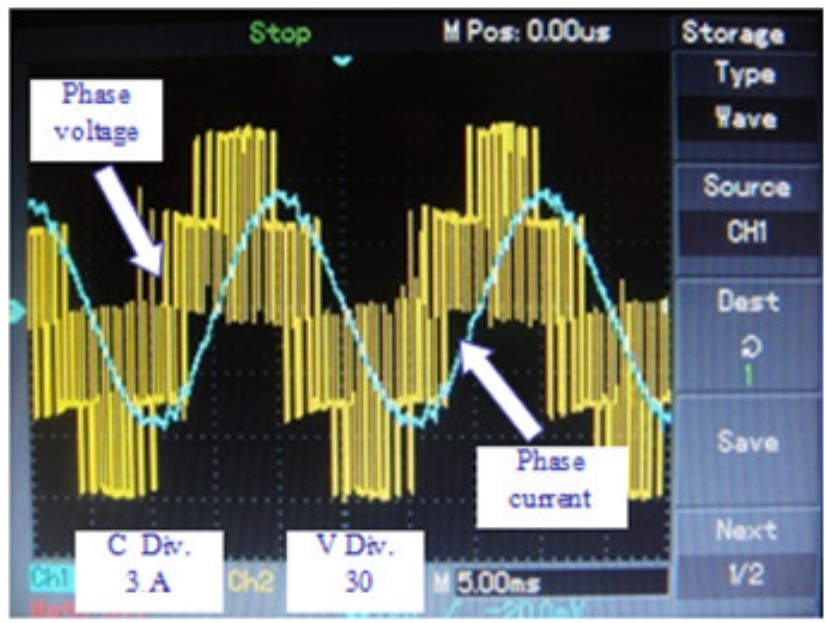

Fig. 15. Motor phase voltage and current 


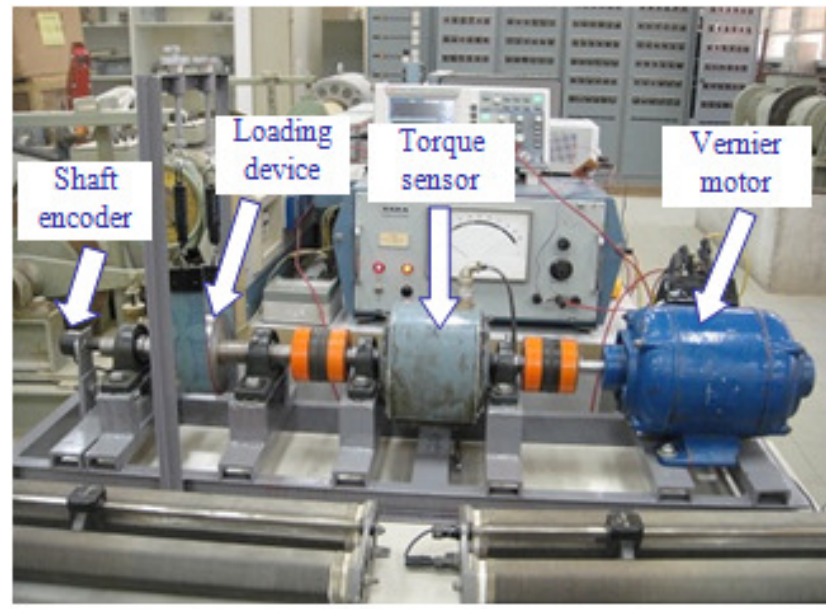

Fig. 16. Motor set for loading test

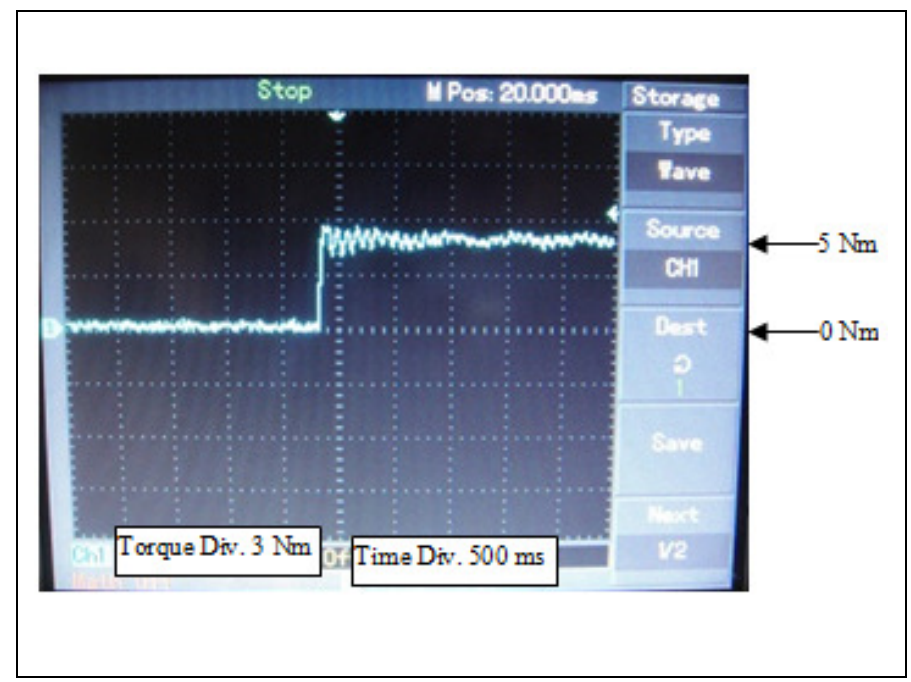

Fig. 17. Motor torque response for $5 \mathrm{Nm}$ sudden load torque

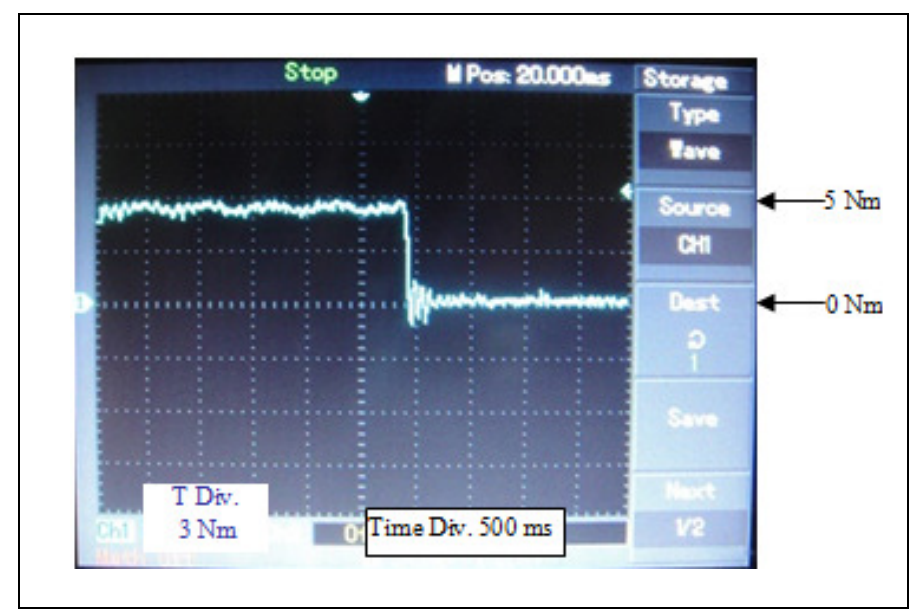

Fig. 18. Motor torque response for no load

\section{CONCLUSIONS}

In this paper, the mathematical model of a HB-type vernier motor was simulated using the Matlab/Simulink software package. To validate the simulation, a test motor was fabricated. Results showed that:

- The motor steady state speed changes linearly with frequency.

- The motor phase voltage and current simulation results are identical with the experimental results.

- The motor speed and torque profiles exhibit small amounts of oscillation due to sudden changes in the shaft load.

\section{REFERENCES:}

[1] H. Suda, Y. Matsushima, L. Xu, and Y. Anazawa, "Analysis of HB-type Vernier motor", IEEJ Transactions on Industry Applications, Vol. 125, No. 3, pp. 270-276, 2005.

[2] H. Suda, Y. Anazawa, "Torque analysis of HB-type Vernier motor", The IEEE International Electric Machines and Drives Conference, IEMDC '07, pp. 709-714, Turkey, 2007.

[3] L Blaisdell, R Rubin, O Mahr, "ATS mechanically despun communications satellite antenna", IEEE Transaction on Antennas and Propagation, Vol. 17, No. 4, pp. 415-528, 1969.

[4] C. H. Lee, "Vernier motor and its design", IEEE Transactions on Power Apparatus and Systems, Vol. 82, No. 66, pp. 343-349, 1963.

[5] A. E. Fitzgerald, C. Kingsley Jr., S. Umans, Electric Machinery, Sixth Edition, McGraw-Hill Companies, Inc., 2003.

[6] C. M. Ong, Dynamic simulation of electric machinery: using Matlab/Simulink, Prentice Hall PTR, 1998.

[7] A. Bonnet, T. Alukaiday, P. C. K. Luk, "A high performance space vector motor drive controller", IEE Colloquium on DSP Chips in Real Time Measurement and Control (Digest No: 1997/301), United Kingdom, 1997. 